\title{
Regenerative Medicine Strategies for Hypoplastic Left Heart Syndrome
}

\author{
Josue Chery, MD, Joshua Wong, MD, Shan Huang, Shuyun Wang, MD, PhD, and Ming-Sing Si, MD ${ }^{1}$
}

\begin{abstract}
Hypoplastic left heart syndrome (HLHS), the most severe and common form of single ventricle congenital heart lesions, is characterized by hypoplasia of the mitral valve, left ventricle (LV), and all LV outflow structures. While advances in surgical technique and medical management have allowed survival into adulthood, HLHS patients have severe morbidities, decreased quality of life, and a shortened lifespan. The single right ventricle $(\mathrm{RV})$ is especially prone to early failure because of its vulnerability to chronic pressure overload, a mode of failure distinct from ischemic cardiomyopathy encountered in acquired heart disease. As these patients enter early adulthood, an emerging epidemic of RV failure has become evident. Regenerative medicine strategies may help preserve or boost RV function in children and adults with HLHS by promoting angiogenesis and mitigating oxidative stress. Rescuing a RV in decompensated failure may also require the creation of new, functional myocardium. Although considerable hurdles remain before their clinical translation, stem cell therapy and cardiac tissue engineering possess revolutionary potential in the treatment of pediatric and adult patients with HLHS who currently have very limited long-term treatment options.
\end{abstract}

Keywords: hypoplastic left heart syndrome, stem cells, tissue engineering, heart failure, congenital heart

\section{Introduction}

Hypoplastic left heart syndrome: definition, epidemiology, and current clinical management

Iingle Ventricle heart Disease is a spectrum of congenital heart defects defined by hypoplasia of the right ventricle $(\mathrm{RV})$ or left ventricle (LV), leaving only one effective pumping chamber to deliver blood flow to both pulmonary and systemic vasculature. Hypoplastic left heart syndrome (HLHS), the most common form of single ventricle heart disease, is characterized by hypoplasia of the mitral valve, LV, and LV outflow structures, which include the aortic valve, ascending aorta, and aortic arch. In HLHS, blood flow into the aorta is dependent on cardiac output generated by the RV passing through the patent ductus arteriosus, a normal fetal structure that connects the pulmonary artery to the aorta. Without intervention, HLHS is uniformly fatal during infancy either from closure of the patent ductus arteriosus or shock due to exuberant blood flow to the lungs and insufficient blood flow to the body.

While the incidence of HLHS is $0.016-0.036 \%$ of all live births, it is responsible for up to $23 \%$ of cardiac deaths during the first week of life and $15 \%$ of cardiac deaths within the first month of life if left untreated. ${ }^{1-3}$ Three-stage palliative surgeries have been the mainstay of treatment for infants born with HLHS since the early 1980s, culminating in the total cavopulmonary anastomosis, or the Fontan procedure, performed at 2-3 years of age. ${ }^{4}$ Upon completion of the Fontan, the arterial and venous circulations are connected in series with the RV providing the lone driving force for systemic blood flow while venous blood drains passively into the lungs.

\section{Results of current clinical management of HLHS}

Although advances in surgical technique and medical management have improved survival into adulthood, HLHS patients suffer decreased quality of life and extensive reliance on medical care due to severe morbidities, including chronic RV failure. One third of these patients die by 25 years of age from end-stage RV failure. ${ }^{5-7}$ This number will undoubtedly increase as more and more patients survive past childhood and represents an emerging epidemic. Heart transplantation remains the only long-term treatment option for HLHS patients with RV failure and is unfortunately far from an optimal treatment due to the shortage of donor organs, need for immunosuppression, and limited lifespan of the allograft. ${ }^{8,9}$ Thus, there is a dire need for novel approaches to preserve and improve the function of the systemic RV, as emphasized recently in a report from a National Heart, Lung, and Blood Institute Working Group. ${ }^{10}$

Departments of ${ }^{1}$ Cardiac Surgery and ${ }^{2}$ Pediatric Cardiology, University of Michigan, Ann Arbor, Michigan. 
The purpose of this review is to introduce HLHS, highlight the mechanisms of RV failure, and review various regenerative medicine approaches and their rational implementation for treating the failing RV in this important clinical entity.

\section{Heart failure in HLHS: key vulnerabilities in the pressure-overloaded RV}

In the normal heart, the RV pressures are $\sim 20 \%$ of systemic arterial (and LV) blood pressure. In HLHS, the RV is required to generate systemic arterial blood pressures during the patient's entire lifetime and is, therefore, prone to early failure. ${ }^{5,11,12}$ Pressure loading creates increased work and stress for the RV. The normal myocardial response to pressure overload is myocyte hypertrophy accompanied by angiogenesis and increased antioxidant enzyme activity to mitigate damage from increased oxidative stress encountered in this setting. ${ }^{13-17}$ Recent evidence has revealed that the $\mathrm{RV}$ is disadvantaged compared with the LV in its molecular adaptation to pressure overload. The angiogenic response in a pressure-overloaded RV is diminished and has been documented in HLHS and pulmonary hypertension. ${ }^{18-22}$ This blunted angiogenic response is believed to lead to an inadequate supply of oxygen and nutrients, thereby causing cardiomyocyte dysfunction. Furthermore, the antioxidant response in the RV is also diminished, thus making the myocardium more susceptible to oxidative injury during pressure loading. ${ }^{23-25}$

Consistent with these molecular mechanisms is strong clinical evidence that the RV does not adapt well to chronic systemic afterload in HLHS. ${ }^{10,12,26-28}$ Therefore, designing regenerative therapies to preserve RV function in HLHS should target both myocardial angiogenesis and oxidative stress. Furthermore, in HLHS patients with advanced stages of RV failure, irreversible damage from chronic ischemia and oxidative injury result in a reduction in the total number of cardiomyocytes. In this situation, regenerative medicine approaches would need to increase the number of viable cardiomyocytes as well as provide a blood vessel network to support this new myocardium.

\section{Regenerative Medicine Strategies For HLHS}

Regenerative medicine approaches to promote myocardial angiogenesis in the pressure-overloaded RV

The normal response to pressure overload is myocyte hypertrophy accompanied by angiogenesis ${ }^{13-15}$ and upregulation of angiogenic signals such as vascular endothelial growth factor A (VEGFA) and angiopoietin-2. ${ }^{29}$ Chronic pressure overload leads to a maladaptive diminution or rarefaction of capillary density. ${ }^{30-32}$ Capillary rarefaction causes ischemia and progression to decompensated heart failure. ${ }^{33,34}$ Various clinical conditions such as hypertension, aortic stenosis, and hypertrophic obstructive cardiomyopathy lead to pressure overload of the LV and result in capillary rarefaction. ${ }^{35-37}$ The RV is also pressure overloaded and subject to capillary rarefaction in diseases such as HLHS and pulmonary hypertension. ${ }^{18-20}$ There is strong clinical evidence that the RV does not adapt well to chronic systemic afterload in HLHS, consistent with the progression and sequela of capillary rarefaction. ${ }^{10,12,26-28}$

Promoting angiogenesis has been shown to prevent LV heart failure in the setting of hypertrophy. ${ }^{38,39}$ A variety of stem cells, including mesenchymal stem cells (MSCs), resident cardiac stem/progenitor cells (CPCs), and endothelial progenitor cells (EPCs), have been demonstrated to stimulate myocardial angiogenesis. Most of these cell therapies have been evaluated for use in LV ischemic heart disease, but are included in our discussion here.

MSCs are believed to reside in the perivascular regions of essentially all tissues and are comprised of a heterogeneous population of plastic adherent cells that do not possess a unique surface marker phenotype. ${ }^{40}$ It is well recognized that MSCs are proangiogenic and secrete numerous angiogenic growth factors. ${ }^{41-49}$ Multiple paracrine and juxtacrine mechanisms exist, by which MSCs promote angiogenesis, indicating a complex and regulated process that is superior to the indiscriminate, forced expression of an angiogenic gene such as VEGFA in the myocardium. ${ }^{50-52}$ Therefore, MSC therapy provides an approach to therapeutic angiogenesis that cannot be replicated by other noncell therapy strategies. Furthermore, MSCs have been demonstrated to possess the ability to differentiate into endothelial cells during 3D culture or when exposed to VEGFA or sphingosine-1-phosphate. ${ }^{53-55}$

MSCs are being evaluated as a therapeutic agent for promoting angiogenesis in various ischemic conditions, but have not been specifically evaluated in the setting of RV pressure-overload hypertrophy. ${ }^{56-64}$ The success of MSCs in treating ischemic conditions depends on their inherent proangiogenic characteristics, and thus numerous investigators have sought to enhance the ability of MSCs to promote angiogenesis by augmenting the expression of various angiogenic signals in these cells. ${ }^{65-70}$ However, genetically modified MSCs face extensive and protracted safety and regulatory hurdles before clinical use, and thus the identification of the most potent proangiogenic MSC sources or subtypes is currently preferable for the most direct pathway to clinical translation. Several studies have examined the proangiogenic potency of MSCs isolated from different tissue sources and ages of tissue source. MSCs derived from adipose, bone marrow, myocardium, and skeletal muscle are all equivalent in promoting angiogenesis. ${ }^{71,72}$ MSCs from other clinically relevant sources, such as umbilical cord, placenta, thymus, and sternum have not been comparatively evaluated in their ability to promote angiogenesis. ${ }^{73-79}$ While the influence of MSC tissue source is unclear, it is evident from existing data that MSCs derived from younger, healthy subjects are more potent in promoting angiogenesis. ${ }^{80-82}$ Yet another approach to increasing the proangiogenic potency of MSCs is to precondition them with hypoxia, growth factors, and small molecules. ${ }^{83-86}$ Ultimately, selection and preparation of the ideal proangiogenic MSC therapeutic product will depend upon ease of isolation, availability of neonatal source tissue, ability to expand these cells, and finding an optimal preconditioning approach.

Cardiac stem/progenitor cells, a subset of stem cells that reside within the myocardium, have the potential to differentiate into cardiomyocytes, smooth muscle cells, and endothelial cells. Injection of exogenous CPCs into models of ischemic heart disease has been shown to exert a paracrine effect that promotes angiogenesis, protect existing cardiomyocytes, and stimulate endogenous CPCs to potentially enhance regeneration. ${ }^{87-91}$ Although no experimental evidence exists of whether CPCs can improve angiogenesis in the pressure-overloaded $\mathrm{RV}$, there is some experience that 
these cells may promote angiogenesis in the pressureoverloaded LV. Mice receiving intravenous administration of CPCs after transverse aortic constriction (a model of LV pressure overload) resulted in increased expression of angiogenic growth factors (such as $b F G F$ ) and density of CD $31+$ endothelial cells. ${ }^{92}$ Cardiac progenitor cells can be isolated from neonates undergoing open heart surgery; however it is unclear whether clinically relevant amounts of these cells can be harvested for patient therapy. ${ }^{93}$ Currently, there is no evidence that CPCs improve angiogenesis in a pressure-overloaded RV.

EPCs belong to a subset of bone marrow-derived cells that are found in the peripheral circulation and aid in endothelial homeostasis as well as angiogenesis. EPCs differentiate into endothelial cells through the activation of an upstream, highly conserved regulator gene named heterochromatin protein 1 alpha $(H P l \alpha)$. Subsequently, a multicellular process ensues that initiates sprouting to culminate in angiogenesis. ${ }^{94,95}$ While the complex biology of EPCs has yet to be fully understood, an inverse correlation between the absolute number of EPCs and cardiovascular risk factors and disease has been elucidated. ${ }^{96-98}$ This has been corroborated by preclinical and clinical studies that demonstrate an improvement in LV function with EPC therapy in the setting of ischemic heart disease. ${ }^{99,100}$ The precise role of EPCs in pressure overload-induced RV failure and potential therapy for this distinct entity has yet to be defined, although some evidence exists that endogenous EPCs are mobilized in experimental models of LV pressure overload. ${ }^{101,102}$

Human umbilical cord blood-derived mononuclear cells (UCBMNCs) were recently described to promote angiogenesis in the pressure-overloaded RV in athymic nude mice. ${ }^{103}$ Human UCBMNCs were injected into the RV 4 weeks after pulmonary artery banding, and animals were euthanized at 8 weeks for histological analysis. Therapy with UCBMNCs resulted in a significantly increased RV myocardial capillary density as compared with untreated controls. Recent evidence indicates that culturing UCBMNCs for 2 weeks yields a heterogeneous collection of cells that is comprised of EPCs and MSCs, but it is unknown if having this combination of both these cell types yield an additive or synergistic proangiogenic effect. ${ }^{104}$

There is convincing evidence that a variety of stem cells can promote angiogenesis in the heart, although most of these findings were obtained in models of acute myocardial ischemia. Further research is needed to determine the ability of these stem cells to promote angiogenesis in the pressureoverloaded RV. The magnitude of therapeutic effect is likely related to the intrinsic proangiogenic potency, and thus identifying a stem cell with especially potent proangiogenic characteristics is important.

\section{Scaffold therapy for HLHS}

Acellular scaffolds are made from synthetic polymers or human or animal extracellular matrix and can be administered in patch form to the appropriate myocardial site and can serve as a platform for endogenous progenitor cell migration and proliferation. Short-term results of both animal models and clinical studies using the FDA-approved porcine small intestinal submucosa (pSIS) demonstrate that the material is suitable for closure of septal defects. However, an inflammatory response with fibrosis is generated without site-specific tissue growth. Moreover, in the pediatric population, pSIS is associated with vessel stenosis and a suboptimal aortic valve repair. ${ }^{105-108}$

Clinical experience with acellular scaffolds suggests that the scaffolds do not regenerate site-specific tissue. Furthermore, they stimulate very little regenerative response for the myocardium, which limits their use as sole therapy. An alternative approach to promote regeneration is to combine acellular scaffolds with stem cell therapy. The scaffolds can serve as a delivery vehicle for stem cells and also prime the stem cells for angiogenesis and regeneration. When pSIS is seeded with either MSCs or CPCs, the stem cells proliferate and differentiate to display early cardiogenic profile. ${ }^{109}$ Another approach that is currently being investigated is to convert the extracellular matrix scaffolds into a hydrogel that can be directly injected, with or without stem cells, into the ischemic myocardium. ${ }^{110-113}$ Other types of hydrogels have also been described and have been supplemented with stromal cell-derived factor $1 \alpha(\operatorname{SDF} 1 \alpha)$, angiogenic peptides, and other instructive growth factors to promote angiogenesis. ${ }^{114-118}$ Preclinical evaluation of acellular scaffolds and injectable hydrogels in small and large animal models of ischemic heart disease has demonstrated efficacy and promotion of angiogenesis. They have not been evaluated in an RV pressure-overload model of heart failure, so its relevance to HLHS is unknown.

\section{Regenerative medicine approaches to alleviate oxidative stress in the pressure-overloaded RV}

Although there are no studies specifically evaluating the utility of regenerative medicine approaches to mitigate oxidative injury in the pressure-overloaded RV, there is strong experimental evidence which demonstrates that a variety of stem cells can provide antioxidative benefit. Endogenous mechanisms to mitigate damage from oxidative stress are largely dependent on antioxidant enzymes. The enzyme superoxide dismutase (SOD) is important in its role as part of an antioxidative defense mechanism in all cells. It catalyzes the dismutation of the damaging superoxide $\left(\mathrm{O}_{2}{ }^{-}\right)$free radical into less damaging $\mathrm{H}_{2} \mathrm{O}_{2}$. There are three isoforms of SOD: SOD1, 2, and 3. SOD1 is located in the cytosol and uses copper and zinc. SOD2 is located in the mitochondria and uses manganese. SOD3 is secreted into the extracellular space and uses copper and zinc. Extracellular SOD3 has been demonstrated to blunt tissue damage and inflammation. ${ }^{119-121}$ Because it is secreted, SOD3 is a potential mediator of the antioxidative property observed in stem cells.

Yang et al. determined that EPCs secrete unidentified soluble factors that protect endothelial cells against oxidative stress, thereby increasing survival and cellular function. ${ }^{122}$ Bone marrow-derived EPCs have also been demonstrated to have therapeutic effects in a dilated cardiomyopathy model in rats with streptozotocin-induced diabetes, and that these beneficial effects are associated with increased expression of SOD2 and decreased apoptosis and fibrosis. ${ }^{123}$ Qiu et al. determined that EPCs protect against cerebral ischemiareperfusion injury in rats, and this therapeutic effect was associated with increased total SOD activity, increased levels of 
the nonenzymatic scavenger, glutathione, and decreased apoptosis in the affected areas. ${ }^{124}$

MSCs have been shown to possess antioxidative effects, which are mediated by extracellular SOD3. DeSantiago et al. determined that mouse bone marrow MSCs protect mouse ventricular cardiomyocytes from ischemia-reperfusion injury in vitro by secretion of SOD3, which can reduce the levels of damaging reactive oxygen species (ROS). ${ }^{125}$ Arslan et al. determined that exosomes secreted by MSCs possess antioxidative properties in a murine model of cardiac ischemiareperfusion injury. ${ }^{126}$ These investigators found that only intact exosomes could improve cardiac function, reduce oxidative stress, and restore bioenergetics after myocardial ischemia-reperfusion injury.

Forced expression of SOD3 in bone marrow-derived MSCs may lead to enhanced therapeutic effects. ${ }^{127}$ Bone marrow MSCs infected with adenovirus-containing SOD3 had a significantly higher survival after transplantation and could provide sustained SOD3 production. This enhanced SOD3 expression was accompanied with a reduction of myocardial infarction-induced oxidative stress, improvement of cardiac function, reduction of fibrosis, and apoptosis after myocardial infarction in rodents. In vitro, bone marrow MSCs expressing SOD3 attenuated cardiomyocyte apoptosis and ROS production and enhanced cardiomyocyte proliferation after hypoxia/serum deprivation.

These results indicate that EPCs and MSCs do possess the ability to neutralize oxidative stress, and that they may provide benefit in mitigating oxidative injury in the pressureoverloaded RV. Stem cells with forced or intrinsically high expression of SOD3 may effectively preserve RV function in HLHS and thus deserve further investigation.

\section{Regenerative medicine approaches to creating new myocardium}

Perhaps one of the boldest and most exciting regenerative medicine approaches to heart failure is the possibility of creating functional heart tissue patches or ventricles in vitro for implantation in patients. Enlarging the LV with engineered heart tissue (EHT) has even been proposed for patients with HLHS. ${ }^{128}$ However, to create a useable LV would require more than adding myocardium to increase LV volume. It would necessitate the creation of a mitral valve, aortic valve, and ascending aorta. Hence curing HLHS by using the tissue engineering approach is a significant challenge that would entail the in vitro creation of functional heart valves, myocardium, and larger arteries.

However, leaving palliated patients with their single ventricle (Fontan) physiology and improving the contractile function of the pressure-overloaded RV would be clinically feasible and perhaps more achievable from a tissue engineering standpoint. EHT would be of benefit in HLHS patients with advanced stages of RV failure and ideally augment cardiac output immediately upon implantation. To fabricate EHT that would accomplish this feat, a large number of contractile human ventricular cardiomyocytes organized in a compact arrangement and supplied by a dense, perfused vascular network is required.

With embryonic stem cells, the advent of induced pluripotent stem cells (iPSCs), and further molecular insights into heart development, derivation of large numbers of human cardiomyocytes is now possible. ${ }^{129}$ One of the key remaining challenges on this front is creating and arranging pure ventricular-type cardiomyocytes, and then arranging these millions to billions of cardiomyocytes, along with fibroblasts, smooth muscle cells, and endothelial cells into the compact, organized fashion seen in native myocardium. Such a construct would require a mature and perfused vasculature to provide the obligatory flow of nutrients and oxygen to supply the cardiomyocytes, especially those deep to the surface of the construct beyond the oxygen diffusion distance. ${ }^{130,131}$ A functioning, perfused microcirculation is paramount, without which central necrosis is observed in tissues greater than $100 \mu \mathrm{m}$ in thickness. ${ }^{132}$ The vascularization problem is one of the most important bottlenecks in the field of tissue engineering as it is otherwise not possible to create adequately sized, functional replacement tissues.

The vasculature of EHT must be multiscalar and multiphenotype to properly distribute energy and mass flow to parenchymal cardiomyocytes. As in the architecture of the native terminal vascular bed, the engineered vascular network must contain a perfused artery ( $\geq 4 \mathrm{~mm}$ diameter), arterioles $(10-200 \mu \mathrm{m})$, capillaries $(4-10 \mu \mathrm{m})$, venules $(10-200 \mu \mathrm{m})$, and a draining vein $(\geq 4 \mathrm{~mm})$ to optimally accomplish their function. The artery and vein must also be at least several millimeters in diameter to make surgical anastomosis to the patient's native vascular network possible.

Most research thus far has focused on the creation of microvasculature in EHT. Most in vitro approaches have incorporated the coculture of cardiomyocytes and endothelial cells with EPCs, fibroblasts, or MSCs. ${ }^{133-135}$ The density of the engineered microvasculature in these EHT constructs are generally at least one order of magnitude less than the capillary density present in native myocardium $\left(5000 / \mathrm{mm}^{2}\right)$. Thus, the thickness of constructs is currently still constrained because the relatively sparse engineered microvasculature lacks perfusion and, therefore, the EHT construct thickness is limited by oxygen diffusion limitations.

There have been recent descriptions of methods to perfuse engineered macro- and microvasculature. Since their seminal description of the perfusion-decellularization method of rat hearts to obtain scaffolds that were then seeded with neonatal rat cardiomyocytes, the group led by Ott has recently followed up with a study of decellularizing human hearts and reseeding with cardiomyocytes derived from human iPSCs. ${ }^{136,137}$ In this method, the scaffold for the native multiscale vascular network is also left intact, and thus can be used to perfuse seeded cardiomyocytes. Furthermore, these investigators have seeded endothelial cells into this perfusable vascular network in an attempt to recreate a living vasculature. ${ }^{136}$ The ultimate success of this strategy to create a vascularized heart tissue (or even entire hearts) is still unclear as the resistance of the endothelial cell-seeded vascular network to the development of thrombosis has not been rigorously studied.

Another ingenious approach that partially borrows from the multiscale vascular bed of native tissue was recently described by Sekine et al. ${ }^{138}$ A pedicle tissue flap based off the femoral vessels of the rat was used as a perfusable tissue bed and serially applied cardiomyocyte cell sheets were then juxtaposed to this perfused vascular bed to generate a thick, vascularized, and perfused EHT construct. This approach 
appears to have great potential, but has yet to be applied to human-derived tissues and EHT.

Perfused engineered vascular networks that do not rely on living or decellularized tissues have been generated with microfluidics technology and 3D bioprinting. ${ }^{139,140}$ These are interesting, "bottom up" engineering approaches to developing perfusable vasculature since they do not require the presence of native vasculature. The microfluidics approach also utilizes the self-organizing ability of human endothelial cells and yields perfusable capillary networks onto which cardiomyocytes can be seeded to yield in vitro models of heart tissue. ${ }^{139,141}$ Expanding this approach to include the generation and incorporation of larger (surgicallyimplantable) vessels has yet to be described. Dai's group described the use of 3D bioprinting to create millimeter scale endothelial cell-lined channels in collagen hydrogels, which were also seeded with endothelial cells. ${ }^{140}$ They generated two perfusable endothelial cell-lined bioprinted channels connected by a capillary network formed from selforganizing endothelial cells between these two channels, resulting in a multiscale, perfusable vascular network. Although vascular communication between the two perfusable larger channels was not demonstrated and cardiomyocytes were not included as parenchymal cells in this engineered vascular network, this is a promising approach to developing EHT with a multiscale, perfusable vascular network.

\section{Stem cell therapy clinical trials for HLHS}

The discovery of cardiomyocyte apoptosis in physiologic states implies that the creation of new cardiomyocytes is necessary to maintain homeostasis ${ }^{142,143}$ This regenerative process may be mediated by CPCs. ${ }^{142}$ While children have a greater quantity of CPCs, the absolute number is not sufficient to correct the anatomic derangements seen in HLHS. ${ }^{93}$ However, these limited cells can be harvested, differentiated, amplified, and potentially used clinically. ${ }^{144,145}$ The precise identification of CPCs has evaded the field. For example, these resident cardiac stem cells can be defined by a surface marker (such as c-kit) or can be defined by its method of derivation, as in the case for cardiosphere-derived cells, a more heterogeneous population of cells. ${ }^{146}$ The phase I clinical trials SCIPIO and CADUCEUS utilized CPCs as treatment for adult-onset, acquired ischemic cardiomyopathy, and results of these trials demonstrated improved LV function and decreased fibrosis. ${ }^{145,147}$

In HLHS patients, the phase I clinical trial TICAP, investigated the use of autologous CPCs, obtained either at the second or third-stage procedure, delivered into the coronary arteries. There were no complications or tumor formation reported within 36 months of CPC administration. Moreover, a clinical improvement of RV ejection fraction and a reduction in brain natriuretic peptide, a biomarker for heart failure, was seen. Currently, a Phase II clinical trial is underway and will examine the effects of CPCs on RV ejection fraction and myocardial fibrosis in more detail. ${ }^{93,148-151}$

Initial use of bone marrow-derived stem cells in the pediatric population with end-stage heart failure was first described through case reports performed for management of dilated cardiomyopathy and RV failure in HLHS. ${ }^{152-154}$ These initial descriptions reported modest improvement in ventricular function and heart failure symptoms based on
New York Heart Association classification. ${ }^{151,153,154}$ However, the benefits were short lived. Moreover, the patients were concurrently treated with sildenafil and erythropoietin, two drugs known to mobilize progenitor cells, as potential confounders in the perceived effects. Recently, Burkhart et al. reported on the safety of intramyocardial injection of autologous umbilical blood-derived cells during the second palliative procedure of a patient with HLHS. ${ }^{155}$ Confounding factors such as deviations in medical and surgical treatment made it difficult to attribute the clinical benefits to stem cell therapy alone. Regardless, these case reports highlight the potential benefit of stem cell therapy in pediatric heart disease, although more research is needed to optimize stem cell therapy for those with HLHS.

\section{Conclusions}

Improvement in the treatment of HLHS has increased survival of some children into adulthood. Nevertheless, the high morbidity and mortality associated with HLHS remains unsatisfactory with an emerging epidemic of RV failure in these patients with no available alternative treatment options. This challenging clinical scenario presents as an ideal situation where regenerative medicine approaches can be applied. Promising preclinical and early clinical evidence suggest that stem cell therapy may be able to preserve the function of the pressure-overloaded RV. Initial case reports and subsequent clinical trials highlight the potential benefits of regenerative medicine in patients with HLHS, while reminding us of the challenges that remain to be conquered. Consequently, further research is required to develop and establish regenerative medicine therapies in the armamentarium of the clinical treatment of HLHS.

\section{Disclosure Statement}

No competing financial interests exist.

\section{References}

1. Samanek, M., Slavik, Z., Zborilova, B., Hrobonova, V., Voriskova, M., and Skovranek, J. Prevalence, treatment, and outcome of heart disease in live-born children: a prospective analysis of 91,823 live-born children. Pediatr Cardiol 10, 205, 1989.

2. Fyler, D.C., Rothman, K.J., Buckley, L.P., Cohn, H.E., Hellenbrand, W.E., and Castaneda, A. The determinants of five year survival of infants with critical congenital heart disease. Cardiovasc Clin 11, 393, 1981.

3. Morris, C.D., Outcalt, J., and Menashe, V.D. Hypoplastic left heart syndrome-natural-history in a geographically defined population. Pediatrics 85, 977, 1990.

4. Norwood, W.I., Lang, P., and Hansen, D.D. Physiologic repair of aortic atresia-hypoplastic left heart syndrome. $\underline{\mathrm{N}}$ Engl J Med 308, 23, 1983.

5. d'Udekem, Y., Iyengar, A.J., Galati, J.C., Forsdick, V., Weintraub, R.G., Wheaton, G.R., Bullock, A., Justo, R.N., Grigg, L.E., Sholler, G.F., Hope, S., Radford, D.J., Gentles, T.L., Celermajer, D.S., and Winlaw, D.S. Redefining expectations of long-term survival after the Fontan procedure: twenty-five years of follow-up from the entire population of Australia and New Zealand. Circulation 130, S32, 2014. 
6. Iyengar, A.J., Winlaw, D.S., Galati, J.C., Wheaton, G.R., Gentles, T.L., Grigg, L.E., Justo, R.N., Radford, D.J., Weintraub, R.G., Bullock, A., Celermajer, D.S., and d'Udekem, Y. The extracardiac conduit Fontan procedure in Australia and New Zealand: hypoplastic left heart syndrome predicts worse early and late outcomes. Eur J Cardiothorac Surg 46, 465, 2014.

7. Arnold, R.R., Loukanov, T., and Gorenflo, M. Hypoplastic left heart syndrome-unresolved issues. Front Pediatr 2, $125,2014$.

8. Chinnock, R.E., and Bailey, L.L. Heart transplantation for congenital heart disease in the first year of life. Curr Cardiol Rev 7, 72, 2011.

9. Bailey, L.L., Nehlsen-Cannarella, S.L., Doroshow, R.W., Jacobson, J.G., Martin, R.D., Allard, M.W., Hyde, M.R., Dang Bui, R.H., and Petry, E.L. Cardiac allotransplantation in newborns as therapy for hypoplastic left heart syndrome. N Engl J Med 315, 949, 1986.

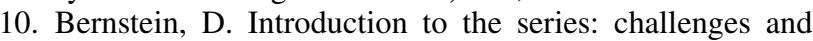
opportunities in pediatric heart failure and transplantation. Circulation 129, 112, 2014.

11. Si, M.S., Pearson, G.D., and Ohye, R.G. Shunt choice in single right ventricle patients: an update. Expert Rev Cardiovasc Ther 11, 1691, 2013.

12. Tham, E.B., Smallhorn, J.F., Kaneko, S., Valiani, S., Myers, K.A., Colen, T.M., Kutty, S., and Khoo, N.S. Insights into the evolution of myocardial dysfunction in the functionally single right ventricle between staged palliations using speckle-tracking echocardiography. J Am Soc Echocardiogr 27, 314, 2014.

13. Hudlicka, O., Brown, M., and Egginton, S. Angiogenesis in skeletal and cardiac-muscle. Physiol Rev 72, 369, 1992.

14. Souders, C.A., Borg, T.K., Banerjee, I., and Baudino, T.A. Pressure overload induces early morphological changes in the heart. Am J Pathol 181, 1226, 2012.

15. Tomanek, R.J., and Torry, R.J. Growth of the coronary vasculature in hypertrophy: mechanisms and model dependence. Cell Mol Biol Res 40, 129, 1994.

16. Kai, H., Mori, T., Tokuda, K., Takayama, N., Tahara, N., Takemiya, K., Kudo, H., Sugi, Y., Fukui, D., Yasukawa, H., Kuwahara, F., and Imaizumi, T. Pressure overloadinduced transient oxidative stress mediates perivascular inflammation and cardiac fibrosis through angiotensin II. Hypertens Res 29, 711, 2006.

17. Sag, C.M., Santos, C.X., and Shah, A.M. Redox regulation of cardiac hypertrophy. J Mol Cell Cardiol 73, 103, 2014.

18. Drake, J.I., Bogaard, H.J., Mizuno, S., Clifton, B., Xie, B., Gao, Y., Dumur, C.I., Fawcett, P., Voelkel, N.F., and Natarajan, R. Molecular signature of a right heart failure program in chronic severe pulmonary hypertension. Am J Respir Cell Mol Biol 45, 1239, 2011.

19. Padalino, M.A., Castellani, C., Toffoli, S., Della Barbera, M., Milanesi, O., Thiene, G., Stellin, G., and Angelini, A. Pathological changes and myocardial remodelling related to the mode of shunting following surgical palliation for hypoplastic left heart syndrome. Cardiol Young 18, 415, 2008.

20. Salih, C., Sheppard, M.N., and Ho, S.Y. Morphometry of coronary capillaries in hypoplastic left heart syndrome. Ann Thorac Surg 77, 903, 2004.

21. Ryan, J.J., and Archer, S.L. The right ventricle in pulmonary arterial hypertension: disorders of metabolism, angiogenesis and adrenergic signaling in right ventricular failure. Circ Res 115, 176, 2014.
22. Sutendra, G., Dromparis, P., Paulin, R., Zervopoulos, S., Haromy, A., Nagendran, J., and Michelakis, E.D. A metabolic remodeling in right ventricular hypertrophy is associated with decreased angiogenesis and a transition from a compensated to a decompensated state in pulmonary hypertension. J Mol Med 91, 1315, 2013.

23. Reddy, S., and Bernstein, D. The vulnerable right ventricle. Curr Opin Pediatr 27, 563, 2015.

24. Ecarnot-Laubriet, A., Rochette, L., Vergely, C., Sicard, P., and Teyssier, J.R. The activation pattern of the antioxidant enzymes in the right ventricle of rat in response to pressure overload is of heart failure type. Heart Dis 5, 308, 2003.

25. Schreckenberg, R., Rebelo, M., Deten, A., Weber, M., Rohrbach, S., Pipicz, M., Csonka, C., Ferdinandy, P., Schulz, R., and Schluter, K.D. Specific mechanisms underlying right heart failure: the missing upregulation of superoxide dismutase- 2 and its decisive role in antioxidative defense. Antioxid Redox Signal 23, 1220, 2015.

26. Kaneko, S., Khoo, N.S., Smallhorn, J.F., and Tham, E.B. Single right ventricles have impaired systolic and diastolic function compared to those of left ventricular morphology. J Am Soc Echocardiogr 25, 1222, 2012.

27. Kutty, S., Graney, B.A., Khoo, N.S., Li, L., Polak, A., Gribben, P., Hammel, J.M., Smallhorn, J.F., and Danford, D.A. Serial assessment of right ventricular volume and function in surgically palliated hypoplastic left heart syndrome using real-time transthoracic three-dimensional echocardiography. J Am Soc Echocardiogr 25, 682, 2012.

28. Sundareswaran, K.S., Kanter, K.R., Kitajima, H.D., Krishnankutty, R., Sabatier, J.F., Parks, W.J., Sharma, S., Yoganathan, A.P., and Fogel, M. Impaired power output and cardiac index with hypoplastic left heart syndrome: a magnetic resonance imaging study. Ann Thorac Surg 82, 1267, 2006.

29. Shiojima, I., Sato, K., Izumiya, Y., Schiekofer, S., Ito, M., Liao, R., Colucci, W.S., and Walsh, K. Disruption of coordinated cardiac hypertrophy and angiogenesis contributes to the transition to heart failure. J Clin Invest 115, 2108, 2005.

30. Anversa, P., Levicky, V., Beghi, C., McDonald, S.L., and Kikkawa, Y. Morphometry of exercise-induced right ventricular hypertrophy in the rat. Circ Res 52, 57, 1983.

31. Anversa, P., and Capasso, J.M. Loss of intermediate-sized coronary-arteries and capillary proliferation after leftventricular failure in rats. Am J Physiol 260, H1552, 1991.

32. Garot, P., Teiger, E., Dupouy, P., Aptecar, E., Hittinger, L., and Dubois-Rande, J.L. Coronary microcirculation and cardiovascular pathology. Drugs 59 Spec No 1, 23, 1999.

33. Oka, T., Akazawa, H., Naito, A.T., and Komuro, I. Angiogenesis and cardiac hypertrophy: maintenance of cardiac function and causative roles in heart failure. Circ Res 114, 565, 2014.

34. Sano, M., Minamino, T., Toko, H., Miyauchi, H., Orimo, M., Qin, Y., Akazawa, H., Tateno, K., Kayama, Y., Harada, M., Shimizu, I., Asahara, T., Hamada, H., Tomita, S., Molkentin, J.D., Zou, Y., and Komuro, I. p53-induced inhibition of Hif-1 causes cardiac dysfunction during pressure overload. Nature 446, 444, 2007.

35. van Deel, E.D., de Boer, M., Kuster, D.W., Boontje, N.M., Holemans, P., Sipido, K.R., van der Velden, J., and Duncker, D.J. Exercise training does not improve cardiac function in compensated or decompensated left ventricular hypertrophy induced by aortic stenosis. J Mol Cell Cardiol 50, 1017, 2011. 
36. Rakusan, K., Flanagan, M.F., Geva, T., Southern, J., and Van Praagh, R. Morphometry of human coronary capillaries during normal growth and the effect of age in left ventricular pressure-overload hypertrophy. Circulation 86, 38, 1992.

37. Pearlman, E.S., Weber, K.T., and Janicki, J.S. Quantitative histology of the hypertrophied human heart. Fed Proc 40, 2042, 1981.

38. Friehs, I., Barillas, R., Vasilyev, N.V., Roy, N., McGowan, F.X., and del Nido, P.J. Vascular endothelial growth factor prevents apoptosis and preserves contractile function in hypertrophied infant heart. Circulation 114, I290, 2006.

39. Hoenig, M.R., Bianchi, C., Rosenzweig, A., and Sellke, F.W. The cardiac microvasculature in hypertension, cardiac hypertrophy and diastolic heart failure. Curr Vasc Pharmacol 6, 292, 2008.

40. Lv, F.J., Tuan, R.S., Cheung, K.M., and Leung, V.Y. Concise review: the surface markers and identity of human mesenchymal stem cells. Stem Cells 32, 1408, 2014.

41. Burlacu, A., Grigorescu, G., Rosca, A.M., Preda, M.B., and Simionescu, M. Factors secreted by mesenchymal stem cells and endothelial progenitor cells have complementary effects on angiogenesis in vitro. Stem Cells Dev 22, 643, 2013.

42. Hung, S.C., Pochampally, R.R., Chen, S.C., Hsu, S.C., and Prockop, D.J. Angiogenic effects of human multipotent stromal cell conditioned medium activate the PI3K-Akt pathway in hypoxic endothelial cells to inhibit apoptosis, increase survival, and stimulate angiogenesis. Stem Cells 25, 2363, 2007.

43. Bronckaers, A., Hilkens, P., Martens, W., Gervois, P., Ratajczak, J., Struys, T., and Lambrichts, I. Mesenchymal stem/stromal cells as a pharmacological and therapeutic approach to accelerate angiogenesis. Pharmacol Therapeut 143, 181, 2014.

44. Carrion, B., Kong, Y.P., Kaigler, D., and Putnam, A.J. Bone marrow-derived mesenchymal stem cells enhance angiogenesis via their alpha 6 beta 1 integrin receptor. Exp Cell Res 319, 2964, 2013.

45. Katare, R., Riu, F., Rowlinson, J., Lewis, A., Holden, R., Meloni, M., Reni, C., Wallrapp, C., Emanueli, C., and Madeddu, P. Perivascular delivery of encapsulated mesenchymal stem cells improves postischemic angiogenesis via paracrine activation of VEGF-A. Arterioscler Thromb Vasc Biol 33, 1872, 2013.

46. Sadat, S., Gehmert, S., Song, Y.H., Yen, Y.S., Bai, X.W., Gaiser, S., Klein, H., and Alt, E. The cardioprotective effect of mesenchymal stem cells is mediated by IGF-1 and VEGF. Biochem Biophys Res Commun 363, 674, 2007.

47. Dufourcq, P., Descamps, B., Tojais, N.F., Leroux, L., Oses, P., Daret, D., Moreau, C., Lamaziere, J.M.D., Couffinhal, T., and Duplaa, C. Secreted frizzled-related protein-1 enhances mesenchymal stem cell function in angiogenesis and contributes to neovessel maturation. Stem Cells 26, 2991, 2008.

48. Kuchroo, P., Dave, V., Vijayan, A., Viswanathan, C., and Ghosh, D. Paracrine factors secreted by umbilical cordderived mscs induce angiogenesis in vitro by a VEGFindependent pathway. Stem Cells Dev 24, 437, 2015.

49. Kong, P., Xie, X., Li, F., Liu, Y., and Lu, Y. Placenta mesenchymal stem cell accelerates wound healing by enhancing angiogenesis in diabetic Goto-Kakizaki (GK) rats. Biochem Biophys Res Commun 438, 410, 2013.
50. Rahbarghazi, R., Nassiri, S.M., Khazraiinia, P., Kajbafzadeh, A.M., Ahmadi, S.H., Mohammadi, E., Molazem, M., and Zamani-Ahmadmahmudi, M. Juxtacrine and Paracrine interactions of rat marrow-derived mesenchymal stem cells, muscle-derived satellite cells, and neonatal cardiomyocytes with endothelial cells in angiogenesis dynamics. Stem Cells Dev 22, 855, 2013.

51. Mohammadi, E., Nassiri, S.M., Rahbarghazi, R., Siavashi, V., and Araghi, A. Endothelial juxtaposition of distinct adult stem cells activates angiogenesis signaling molecules in endothelial cells. Cell Tissue Res 362, 597, 2015.

52. Shyu, K.G., Wang, B.W., Hung, H.F., Chang, C.C., and Shih, D.T.B. Mesenchymal stem cells are superior to angiogenic growth factor genes for improving myocardial performance in the mouse model of acute myocardial infarction. J Biomed Sci 13, 47, 2006.

53. Ikhapoh, I.A., Pelham, C.J., and Agrawal, D.K. Sry-type HMG box 18 contributes to the differentiation of bone marrow-derived mesenchymal stem cells to endothelial cells. Differentiation 89, 87, 2015.

54. Qiu, X., Zhang, Y., Zhao, X., Zhang, S., Wu, J., Guo, H., and $\mathrm{Hu}, \mathrm{Y}$. Enhancement of endothelial differentiation of adipose derived mesenchymal stem cells by a three-dimensional culture system of microwell. Biomaterials 53, 600, 2015.

55. Lu, W., Xiu, X., Zhao, Y., and Gui, M. Improved proliferation and differentiation of bone marrow mesenchymal stem cells into vascular endothelial cells with sphingosine 1-phosphate. Transplant Proc 47, 2035, 2015.

56. Konstanty-Kalandyk, J., Piatek, J., Miszalski-Jamka, T., Rudzinski, P., Walter, Z., Bartus, K., Urbanczyk-Zawadzka, M., and Sadowski, J. The combined use of transmyocardial laser revascularisation and intramyocardial injection of bone-marrow derived stem cells in patients with end-stage coronary artery disease: one year follow-up. Kardiol Pol 71, 485, 2013.

57. Gupta, P.K., Chullikana, A., Parakh, R., Desai, S., Das, A., Gottipamula, S., Krishnamurthy, S., Anthony, N., Pherwani, A., and Majumdar, A.S. A double blind randomized placebo controlled phase I/II study assessing the safety and efficacy of allogeneic bone marrow derived mesenchymal stem cell in critical limb ischemia. $\underline{\mathrm{J} \text { Transl }}$ Med 11, 143, 2013.

58. Mathiasen, A.B., Haack-Sorensen, M., Jorgensen, E., and Kastrup, J. Autotransplantation of mesenchymal stromal cells from bone-marrow to heart in patients with severe stable coronary artery disease and refractory angina-final 3-year follow-up. Int J Cardiol 170, 246, 2013.

59. Lasala, G.P., Silva, J.A., and Minguell, J.J. Therapeutic angiogenesis in patients with severe limb ischemia by transplantation of a combination stem cell product. $\underline{J}$ Thorac Cardiovasc Surg 144, 377, 2012.

60. Karantalis, V., DiFede, D.L., Gerstenblith, G., Pham, S., Symes, J., Zambrano, J.P., Fishman, J., Pattany, P., McNiece, I., Conte, J., Schulman, S., Wu, K., Shah, A., Breton, E., Davis-Sproul, J., Schwarz, R., Feigenbaum, G., Mushtaq, M., Suncion, V.Y., Lardo, A.C., Borrello, I., Mendizabal, A., Karas, T.Z., Byrnes, J., Lowery, M., Heldman, A.W., and Hare, J.M. Autologous mesenchymal stem cells produce concordant improvements in regional function, tissue perfusion, and fibrotic burden when administered to patients undergoing coronary artery bypass grafting. Circ Res 114, 1302, 2014.

61. Heldman, A.W., DiFede, D.L., Fishman, J.E., Zambrano, J.P., Trachtenberg, B.H., Karantalis, V., Mushtaq, M., 
Williams, A.R., Suncion, V.Y., McNiece, I.K., Ghersin, E., Soto, V., Lopera, G., Miki, R., Willens, H., Hendel, R., Mitrani, R., Pattany, P., Feigenbaum, G., Oskouei, B., Byrnes, J., Lowery, M.H., Sierra, J., Pujol, M.V., Delgado, C., Gonzalez, P.J., Rodriguez, J.E., Bagno, L.L., Rouy, D., Altman, P., Foo, C.W.P., da Silva, J., Anderson, E., Schwarz, R., Mendizabal, A., and Hare, J.M. Transendocardial Mesenchymal Stem Cells and Mononuclear Bone Marrow Cells for Ischemic Cardiomyopathy The TACHFT Randomized Trial. JAMA 311, 62, 2014.

62. Hess, D.C., Sila, C.A., Furlan, A.J., Wechsler, L.R., Switzer, J.A., and Mays, R.W. A double-blind placebocontrolled clinical evaluation of MultiStem for the treatment of ischemic stroke. Int J Stroke 9, 381, 2014.

63. George, R., and Lardo, A. Comparison of allogeneic vs autologous bone marrow-derived mesenchymal stem cells delivered by transendocardial injection in patients with ischemic cardiomyopathy: the POSEIDON randomized trial (vol. 308, pg 2369, 2012). JAMA 310, 750, 2013.

64. Lu, D.B., Chen, B., Liang, Z.W., Deng, W.Q., Jiang, Y.Z., Li, S.F., Xu, J., Wu, Q.N., Zhang, Z.H., Xie, B., and Chen, S.H. Comparison of bone marrow mesenchymal stem cells with bone marrow-derived mononuclear cells for treatment of diabetic critical limb ischemia and foot ulcer: a double-blind, randomized, controlled trial. Diabetes Res Clin Pract 92, 26, 2011.

65. Chen, X.Q., Chen, L.L., Fan, L., Fang, J., Chen, Z.Y., and Li, W.W. Stem cells with FGF4-bFGF fused gene enhances the expression of bFGF and improves myocardial repair in rats. Biochem Biophys Res Commun 447, 145, 2014.

66. Han, Y., Tao, R., Han, Y., Sun, T., Chai, J., Xu, G., and Liu, J. Microencapsulated VEGF gene-modified umbilical cord mesenchymal stromal cells promote the vascularization of tissue-engineered dermis: an experimental study. Cytotherapy 16, 160, 2014.

67. HoWangYin, K.Y., Loinard, C., Bakker, W., Guerin, C.L., Vilar, J., D'Audigier, C., Mauge, L., Bruneval, P., Emmerich, J., Levy, B.I., Pouyssegur, J., Smadja, D.M., and Silvestre, J.S. HIF-prolyl hydroxylase 2 inhibition enhances the efficiency of mesenchymal stem cell-based therapies for the treatment of critical limb ischemia. Stem Cells 32, 231, 2014.

68. $\bar{Z}$ Zhang, T., Lee, Y.W., Rui, Y.F., Cheng, T.Y., and Li, G. Bone marrow-derived mesenchymal stem cells promote angiogenesis and growth of breast and prostate tumors. Cytotherapy 15, S15, 2013.

69. Zhao, M.Z., Nonoguchi, N., Ikeda, N., Watanabe, T., Furutama, D., Miyazawa, D., Funakoshi, H., Kajimoto, Y., Nakamura, T., Dezawa, M., Shibata, M.A., Otsuki, Y., Coffin, R.S., Liu, W.D., Kuroiwa, T., and Miyatake, S. Novel therapeutic strategy for stroke in rats by bone marrow stromal cells and ex vivo HGF gene transfer with HSV-1 vector. J Cereb Blood Flow Metab 26, 1176, 2006.

70. Fierro, F.A., Kalomoiris, S., Sondergaard, C.S., and Nolta, J.A. Effects on proliferation and differentiation of multipotent bone marrow stromal cells engineered to express growth factors for combined cell and gene therapy. Stem Cells 29, 1727, 2011.

71. Ma, J.L., Yang, F., Both, S.K., Prins, H.J., Helder, M.N., Pan, J.L., Cui, F.Z., Jansen, J.A., and van den Beucken, J.J.J.P. In vitro and in vivo angiogenic capacity of BMMSCs/HUVECs and AT-MSCs/HUVECs cocultures. Biofabrication 6, 015005, 2014.
72. Lin, R.Z., Moreno-Luna, R., Zhou, B., Pu, W.T., and Melero-Martin, J.M. Equal modulation of endothelial cell function by four distinct tissue-specific mesenchymal stem cells. Angiogenesis 15, 443, 2012.

73. Arutyunyan, I., Fatkhudinov, T., Kananykhina, E., Usman, N., Elchaninov, A., Makarov, A., Bolshakova, G., Goldshtein, D., and Sukhikh, G. Role of VEGF-A in angiogenesis promoted by umbilical cord-derived mesenchymal stromal/stem cells: in vitro study. Stem Cell Res Ther 7, 46, 2016.

74. Shen, C., Lie, P., Miao, T., Yu, M., Lu, Q., Feng, T., Li, J., $\mathrm{Zu}, \mathrm{T}$., Liu, X., and Li, H. Conditioned medium from umbilical cord mesenchymal stem cells induces migration and angiogenesis. Mol Med Rep 12, 20, 2015.

75. Kuchroo, P., Dave, V., Vijayan, A., Viswanathan, C., and Ghosh, D. Paracrine factors secreted by umbilical cordderived mesenchymal stem cells induce angiogenesis in vitro by a VEGF-independent pathway. Stem Cells Dev 24, 437, 2015.

76. Xie, N., Li, Z., Adesanya, T.M., Guo, W., Liu, Y., Fu, M., Kilic, A., Tan, T., Zhu, H., and Xie, X. Transplantation of placenta-derived mesenchymal stem cells enhances angiogenesis after ischemic limb injury in mice. $\mathrm{J}$ Cell Mol Med 20, 29, 2016.

77. Kinzer, M., Hingerl, K., Konig, J., Reinisch, A., Strunk, D., Huppertz, B., and Lang, I. Mesenchymal stromal cells from the human placenta promote neovascularization in a mouse model in vivo. Placenta 35, 517, 2014.

78. Wang, S., Mundada, L., Johnson, S., Wong, J., Witt, R., Ohye, R.G., and Si, M.S. Characterization and angiogenic potential of human neonatal and infant thymus mesenchymal stromal cells. Stem Cells Transl Med 4, 339, 2015.

79. Wang, S., Mundada, L., Colomb, E., Ohye, R.G., and Si, M.S. Mesenchymal stem/stromal cells from discarded neonatal sternal tissue: in vitro characterization and angiogenic properties. Stem Cells Int 2016, 5098747, 2016.

80. Choudhery, M.S., Khan, M., Mahmood, R., Mehmood, A., Khan, S.N., and Riazuddin, S. Bone marrow derived mesenchymal stem cells from aged mice have reduced wound healing, angiogenesis, proliferation and antiapoptosis capabilities. Cell Biol Int 36, 747, 2012.

81. Fan, M., Chen, W., Liu, W., Du, G.Q., Jiang, S.L., Tian, W.C., Sun, L., Li, R.K., and Tian, H. The effect of age on the efficacy of human mesenchymal stem cell transplantation after a myocardial infarction. Rejuvenation Res 13, 429, 2010.

82. Khan, M., Mohsin, S., Khan, S.N., and Riazuddin, S. Repair of senescent myocardium by mesenchymal stem cells is dependent on the age of donor mice. J Cell Mol Med 15, 1515, 2011.

83. Liu, X.B., Wang, J.A., Ji, X.Y., Yu, S.P., and Wei, L. Preconditioning of bone marrow mesenchymal stem cells by prolyl hydroxylase inhibition enhances cell survival and angiogenesis in vitro and after transplantation into the ischemic heart of rats. Stem Cell Res Ther 5, 111, 2014.

84. Herrmann, J.L., Wang, Y., Abarbanell, A.M., Weil, B.R., Tan, J.N., and Meldrum, D.R. Preconditioning mesenchymal stem cells with transforming growth factor-alpha improves mesenchymal stem cell-mediated cardioprotection. Shock 33, 24, 2010.

85. Bader, A.M., Klose, K., Bieback, K., Korinth, D., Schneider, M., Seifert, M., Choi, Y.H., Kurtz, A., Falk, V., and Stamm, C. Hypoxic preconditioning increases survival and pro-angiogenic capacity of human cord blood 
mesenchymal stromal cells in vitro. PLoS One 10, e0138477, 2015.

86. Kang, H., Kim, K.H., Lim, J., Kim, Y.S., Heo, J., Choi, J., Jeong, J., Kim, Y., Kim, S.W., Oh, Y.M., Choo, M.S., Son, J., Kim, S.J., Yoo, H.J., Oh, W., Choi, S.J., Lee, S.W., and Shin, D.M. The therapeutic effects of human mesenchymal stem cells primed with sphingosine-1 phosphate on pulmonary artery hypertension. Stem Cells Dev 24, 1658, 2015.

87. Huang, C.Y., Gu, H.M., Yu, Q., Manukyan, M.C., Poynter, J.A., and Wang, M.J. Sca-1+ cardiac stem cells mediate acute cardioprotection via paracrine factor SDF-1 following myocardial ischemia/reperfusion. PLoS One 6, e29246, 2011.

88. Tseliou, E., Pollan, S., Malliaras, K., Terrovitis, J., Sun, B.M., Galang, G., Marban, L., Luthringer, D., and Marban, E. Allogeneic cardiospheres safely boost cardiac function and attenuate adverse remodeling after myocardial infarction in immunologically mismatched rat strains. J Am Coll Cardiol 61, 1108, 2013.

89. Cheng, K., Malliaras, K., Smith, R.R., Shen, D., Sun, B., Blusztajn, A., Xie, Y., Ibrahim, A., Aminzadeh, M.A., Liu, W., Li, T.S., De Robertis, M.A., Marban, L., Czer, L.S., Trento, A., and Marban, E. Human cardiospherederived cells from advanced heart failure patients exhibit augmented functional potency in myocardial repair. JACC Heart Fail 2, 49, 2014.

90. Hou, L., Kim, J.J., Woo, Y.J., and Huang, N.F. Stem cellbased therapies to promote angiogenesis in ischemic cardiovascular disease. Am J Physiol Heart Circ Physiol 310, H455, 2016.

91. Nakanishi, C., Yamagishi, M., Yamahara, K., Hagino, I., Mori, H., Sawa, Y., Yagihara, T., Kitamura, S., and Nagaya, N. Activation of cardiac progenitor cells through paracrine effects of mesenchymal stem cells. Biochem Biophys Res Commun 374, 11, 2008.

92. Kazakov, A., Meier, T., Werner, C., Hall, R., Klemmer, B., Korbel, C., Lammert, F., Maack, C., Bohm, M., and Laufs, U. C-kit(+) resident cardiac stem cells improve left ventricular fibrosis in pressure overload. Stem Cell Res 15, 700, 2015.

93. Simpson, D.L., Mishra, R., Sharma, S., Goh, S.K., Deshmukh, S., and Kaushal, S. A strong regenerative ability of cardiac stem cells derived from neonatal hearts. Circulation 126, S46, 2012.

94. Maeng, Y.S., Kwon, J.Y., Kim, E.K., and Kwon, Y.G. Heterochromatin protein 1 alpha (HP1alpha: CBX5) is a key regulator in differentiation of endothelial progenitor cells to endothelial Cells. Stem Cells 33, 1512, 2015.

95. Werner, N., Kosiol, S., Schiegl, T., Ahlers, P., Walenta, K., Link, A., Bohm, M., and Nickenig, G. Circulating endothelial progenitor cells and cardiovascular outcomes. N Engl J Med 353, 999, 2005.

96. Hoenig, M.R., Bianchi, C., and Sellke, F.W. Hypoxia inducible factor-1 alpha, endothelial progenitor cells, monocytes, cardiovascular risk, wound healing, cobalt and hydralazine: a unifying hypothesis. Curr Drug Targets 9, 422, 2008.

97. Moon, J.H., Chae, M.K., Kim, K.J., Kim, H.M., Cha, B.S., Lee, H.C., Kim, Y.J., and Lee, B.W. Decreased endothelial progenitor cells and increased serum glycated albumin are independently correlated with plaque-forming carotid artery atherosclerosis in type 2 diabetes patients without documented ischemic disease. Circ J 76, 2273, 2012.
98. Fadini, G.P., Miorin, M., Facco, M., Bonamico, S., Baesso, I., Grego, F., Menegolo, M., de Kreutzenberg, S.V., Tiengo, A., Agostini, C., and Avogaro, A. Circulating endothelial progenitor cells are reduced in peripheral vascular complications of type 2 diabetes mellitus. $\mathbf{J}$ Am Coll Cardiol 45, 1449, 2005.

99. Lee, F.Y., Chen, Y.L., Sung, P.H., Ma, M.C., Pei, S.N., Wu, C.J., Yang, C.H., Fu, M., Ko, S.F., Leu, S., and Yip, H.K. Intracoronary transfusion of circulation-derived CD34+ cells improves left ventricular function in patients with end-stage diffuse coronary artery disease unsuitable for coronary intervention. Crit Care Med 43, 2117, 2015.

100. Atluri, P., Miller, J.S., Emery, R.J., Hung, G., Trubelja, A., Cohen, J.E., Lloyd, K., Han, J., Gaffey, A.C., MacArthur, J.W., Chen, C.S., and Woo, Y.J. Tissue-engineered, hydrogel-based endothelial progenitor cell therapy robustly revascularizes ischemic myocardium and preserves ventricular function. J Thorac Cardiovasc Surg 148, $1090,2014$.

101. Finan, A., Kiedrowski, M., Turturice, B.A., Sopko, N.A., and Penn, M.S. Cardiac pressure overload initiates a systemic stem cell response. Cytotherapy 14, 983, 2012.

102. Mueller, P., Kazakov, A., Semenov, A., Boehm, M., and Laufs, U. Pressure-induced cardiac overload induces upregulation of endothelial and myocardial progenitor cells. Cardiovasc Res 77, 151, 2008.

103. Oommen, S., Yamada, S., Peral, S.C., Campbell, K.A., Bruinsma, E.S., Terzic, A., and Nelson, T.J. Human umbilical cord blood-derived mononuclear cells improve murine ventricular function upon intramyocardial delivery in right ventricular chronic pressure overload. Stem Cell Res Ther 6, 50, 2015.

104. Kim, S.W., Jin, H.L., Kang, S.M., Kim, S., Yoo, K.J., Jang, Y., Kim, H.O., and Yoon, Y.S. Therapeutic effects of late outgrowth endothelial progenitor cells or mesenchymal stem cells derived from human umbilical cord blood on infarct repair. Int J Cardiol 203, 498, 2016.

105. Padalino, M.A., Quarti, A., Angeli, E., Frigo, A.C., Vida, V.L., Pozzi, M., Gargiulo, G., and Stellin, G. Early and mid-term clinical experience with extracellular matrix scaffold for congenital cardiac and vascular reconstructive surgery: a multicentric Italian studydagger. Interact Cardiovasc Thorac Surg 21, 40, 2015.

106. Rosario-Quinones, F., Magid, M.S., Yau, J., Pawale, A., and Nguyen, K. Tissue reaction to porcine intestinal Submucosa (CorMatrix) implants in pediatric cardiac patients: a single-center experience. Ann Thorac Surg 99, 1373, 2015.

107. Ramos, C.M., Francisco, J.C., Olandoski, M., Carvalho, K.A., Cunha, R., Erbano, B.O., Jorge, L.F., Baena, C.P., Amaral, V.F., Noronha, L., Macedo, R.M., Faria-Neto, J.R., and Guarita-Souza, L.C. Myocardial regeneration after implantation of porcine small intestinal submucosa in the left ventricle. Rev Bras Cir Cardiovasc 29, 202, 2014.

108. Witt, R.G., Raff, G., Van Gundy, J., Rodgers-Ohlau, M., and Si, M.S. Short-term experience of porcine small intestinal submucosa patches in paediatric cardiovascular surgery. Eur J Cardiothorac Surg 44, 72, 2013.

109. Hodonsky, C., Mundada, L., Wang, S., Witt, R., Raff, G., Kaushal, S., and Si, M.S. Effects of scaffold material used in cardiovascular surgery on mesenchymal stem cells and cardiac progenitor cells. Ann Thorac Surg 99, 605, 2015. 
110. Okada, M., Payne, T.R., Oshima, H., Momoi, N., Tobita, K., and Huard, J. Differential efficacy of gels derived from small intestinal submucosa as an injectable biomaterial for myocardial infarct repair. Biomaterials 31, 7678, 2010.

111. Slaughter, M.S., Soucy, K.G., Matheny, R.G., Lewis, B.C., Hennick, M.F., Choi, Y., Monreal, G., Sobieski, M.A., Giridharan, G.A., and Koenig, S.C. Development of an extracellular matrix delivery system for effective intramyocardial injection in ischemic tissue. ASAIO J 60, $730,2014$.

112. Toeg, H.D., Tiwari-Pandey, R., Seymour, R., Ahmadi, A., Crowe, S., Vulesevic, B., Suuronen, E.J., and Ruel, M. Injectable small intestine submucosal extracellular matrix in an acute myocardial infarction model. Ann Thorac Surg 96, 1686, 2013.

113. Johnson, T.D., Braden, R.L., and Christman, K.L. Injectable ECM scaffolds for cardiac repair. Methods Mol Biol 1181, 109, 2014.

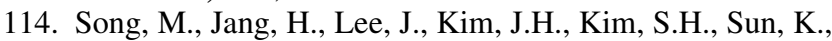
and Park, Y. Regeneration of chronic myocardial infarction by injectable hydrogels containing stem cell homing factor SDF-1 and angiogenic peptide Ac-SDKP. Biomaterials 35, 2436, 2014.

115. Abdalla, S., Makhoul, G., Duong, M., Chiu, R.C., and Cecere, R. Hyaluronic acid-based hydrogel induces neovascularization and improves cardiac function in a rat model of myocardial infarction. Interact Cardiovasc Thorac Surg 17, 767, 2013.

116. MacArthur, J.W., Jr., Purcell, B.P., Shudo, Y., Cohen, J.E., Fairman, A., Trubelja, A., Patel, J., Hsiao, P., Yang, E., Lloyd, K., Hiesinger, W., Atluri, P., Burdick, J.A., and Woo, Y.J. Sustained release of engineered stromal cellderived factor 1-alpha from injectable hydrogels effectively recruits endothelial progenitor cells and preserves ventricular function after myocardial infarction. Circulation 128, S79, 2013.

117. Chiu, L.L., Reis, L.A., Momen, A., and Radisic, M. Controlled release of thymosin beta4 from injected collagen-chitosan hydrogels promotes angiogenesis and prevents tissue loss after myocardial infarction. Regen Med 7, 523, 2012.

118. Salimath, A.S., Phelps, E.A., Boopathy, A.V., Che, P.L., Brown, M., Garcia, A.J., and Davis, M.E. Dual delivery of hepatocyte and vascular endothelial growth factors via a protease-degradable hydrogel improves cardiac function in rats. PLoS One 7, e50980, 2012.

119. Lob, H.E., Marvar, P.J., Guzik, T.J., Sharma, S., McCann, L.A., Weyand, C., Gordon, F.J., and Harrison, D.G. Induction of hypertension and peripheral inflammation by reduction of extracellular superoxide dismutase in the central nervous system. Hypertension 55, 277, 2010.

120. Laurila, J.P., Laatikainen, L.E., Castellone, M.D., and Laukkanen, M.O. SOD3 reduces inflammatory cell migration by regulating adhesion molecule and cytokine expression. PLoS One 4, e5786, 2009.

121. Rabbani, Z.N., Anscher, M.S., Folz, R.J., Archer, E., Huang, H., Chen, L., Golson, M.L., Samulski, T.S., Dewhirst, M.W., and Vujaskovic, Z. Overexpression of extracellular superoxide dismutase reduces acute radiation induced lung toxicity. BMC Cancer 5, 59, 2005.

122. Yang, Z., von Ballmoos, M.W., Faessler, D., Voelzmann, J., Ortmann, J., Diehm, N., Kalka-Moll, W., Baumgartner, I., Di Santo, S., and Kalka, C. Paracrine factors secreted by endothelial progenitor cells prevent oxidative stress- induced apoptosis of mature endothelial cells. Atherosclerosis 211, 103, 2010.

123. Cheng, Y., Guo, S., Liu, G., Feng, Y., Yan, B., Yu, J., Feng, K., and Li, Z. Transplantation of bone marrowderived endothelial progenitor cells attenuates myocardial interstitial fibrosis and cardiac dysfunction in streptozotocin-induced diabetic rats. Int J Mol Med 30, 870, 2012.

124. Qiu, J., Li, W., Feng, S., Wang, M., and He, Z. Transplantation of bone marrow-derived endothelial progenitor cells attenuates cerebral ischemia and reperfusion injury by inhibiting neuronal apoptosis, oxidative stress and nuclear factor-kappaB expression. Int J Mol Med 31, 91, 2013.

125. DeSantiago, J., Bare, D.J., and Banach, K. Ischemia/Reperfusion injury protection by mesenchymal stem cell derived antioxidant capacity. Stem Cells Dev 22, 2497, 2013.

126. Arslan, F., Lai, R.C., Smeets, M.B., Akeroyd, L., Choo, A., Aguor, E.N., Timmers, L., van Rijen, H.V., Doevendans, P.A., Pasterkamp, G., Lim, S.K., and de Kleijn, D.P. Mesenchymal stem cell-derived exosomes increase ATP levels, decrease oxidative stress and activate PI3K/ Akt pathway to enhance myocardial viability and prevent adverse remodeling after myocardial ischemia/reperfusion injury. Stem Cell Res 10, 301, 2013.

127. Pan, Q., Qin, X., Ma, S., Wang, H., Cheng, K., Song, X., Gao, H., Wang, Q., Tao, R., Wang, Y., Li, X., Xiong, L., and Cao, F. Myocardial protective effect of extracellular superoxide dismutase gene modified bone marrow mesenchymal stromal cells on infarcted mice hearts. Theranostics 4, 475, 2014.

128. Zimmermann, W.H., and Cesnjevar, R. Cardiac tissue engineering: implications for pediatric heart surgery. Pediatr Cardiol 30, 716, 2009.

129. Hartman, M.E., Dai, D.F., and Laflamme, M.A. Human pluripotent stem cells: prospects and challenges as a source of cardiomyocytes for in vitro modeling and cellbased cardiac repair. Adv Drug Deliv Rev 96, 3, 2016.

130. Sekine, H., Shimizu, T., Hobo, K., Sekiya, S., Yang, J., Yamato, M., Kurosawa, H., Kobayashi, E., and Okano, T. Endothelial cell coculture within tissue-engineered cardiomyocyte sheets enhances neovascularization and improves cardiac function of ischemic hearts. Circulation 118, S145, 2008.

131. Tulloch, N.L., Muskheli, V., Razumova, M.V., Korte, F.S., Regnier, M., Hauch, K.D., Pabon, L., Reinecke, H., and Murry, C.E. Growth of engineered human myocardium with mechanical loading and vascular coculture. Circ Res 109, 47, 2011.

132. Patra, C., Boccaccini, A.R., and Engel, F.B. Vascularisation for cardiac tissue engineering: the extracellular matrix. Thromb Haemost 113, 532, 2015.

133. Sun, X., Altalhi, W., and Nunes, S.S. Vascularization strategies of engineered tissues and their application in cardiac regeneration. Adv Drug Deliv Rev 96, 183, 2016.

134. Lesman, A., Gepstein, L., and Levenberg, S. Cell triculture for cardiac vascularization. Methods Mol Biol 1181, 131, 2014.

135. Coulombe, K.L.K., Bajpai, V.K., Andreadis, S.T., and Murry, C.E. Heart Regeneration with engineered myocardial tissue. Annu Rev Biomed Eng 16, 1, 2014.

136. Ott, H.C., Matthiesen, T.S., Goh, S.K., Black, L.D., Kren, S.M., Netoff, T.I., and Taylor, D.A. Perfusion-decellularized 
matrix: using nature's platform to engineer a bioartificial heart. Nat Med 14, 213, 2008.

137. Guyette, J.P., Charest, J.M., Mills, R.W., Jank, B.J., Moser, P.T., Gilpin, S.E., Gershlak, J.R., Okamoto, T., Gonzalez, G., Milan, D.J., Gaudette, G.R., and Ott, H.C. Bioengineering human myocardium on native extracellular matrix. Circ Res 118, 56, 2016.

138. Sekine, H., Shimizu, T., Sakaguchi, K., Dobashi, I., Wada, M., Yamato, M., Kobayashi, E., Umezu, M., and Okano, T. In vitro fabrication of functional three-dimensional tissues with perfusable blood vessels. Nat Commun 4, 1399, 2013.

139. Moya, M.L., Hsu, Y.H., Lee, A.P., Hughes, C.C.W., and George, S.C. In vitro perfused human capillary networks. Tissue Eng Part C Methods 19, 730, 2013.

140. Lee, V.K., Lanzi, A.M., Ngo, H., Yoo, S.S., Vincent, P.A., and Dai, G.H. Generation of multi-scale vascular network system within 3D hydrogel using 3D bio-printing technology. Cell Mol Bioeng 7, 460, 2014.

141. Kurokawa, Y.K., and George, S.C. Tissue engineering the cardiac microenvironment: multicellular microphysiological systems for drug screening. Adv Drug Deliv Rev 96, 225, 2016.

142. Nadal-Ginard, B., Kajstura, J., Anversa, P., and Leri, A. A matter of life and death: cardiac myocyte apoptosis and regeneration. J Clin Invest 111, 1457, 2003.

143. Olivetti, G., Abbi, R., Quaini, F., Kajstura, J., Cheng, W., Nitahara, J.A., Quaini, E., Di Loreto, C., Beltrami, C.A., Krajewski, S., Reed, J.C., and Anversa, P. Apoptosis in the failing human heart. N Engl J Med 336, 1131, 1997.

144. Bearzi, C., Rota, M., Hosoda, T., Tillmanns, J., Nascimbene, A., De Angelis, A., Yasuzawa-Amano, S., Trofimova, I., Siggins, R.W., Lecapitaine, N., Cascapera, S., Beltrami, A.P., D’Alessandro, D.A., Zias, E., Quaini, F., Urbanek, K., Michler, R.E., Bolli, R., Kajstura, J., Leri, A., and Anversa, P. Human cardiac stem cells. Proc Natl Acad Sci U S A 104, 14068, 2007.

145. Bolli, R., Chugh, A.R., D’Amario, D., Loughran, J.H., Stoddard, M.F., Ikram, S., Beache, G.M., Wagner, S.G., Leri, A., Hosoda, T., Sanada, F., Elmore, J.B., Goichberg, P., Cappetta, D., Solankhi, N.K., Fahsah, I., Rokosh, D.G., Slaughter, M.S., Kajstura, J., and Anversa, P. Cardiac stem cells in patients with ischaemic cardiomyopathy (SCIPIO): initial results of a randomised phase 1 trial. Lancet 378, 1847, 2011.

146. Loughran, J.H., Elmore, J.B., Waqar, M., Chugh, A.R., and Bolli, R. Cardiac stem cells in patients with ischemic cardiomyopathy: discovery, translation, and clinical investigation. Curr Atheroscler Rep 14, 491, 2012.

147. Makkar, R.R., Smith, R.R., Cheng, K., Malliaras, K., Thomson, L.E., Berman, D., Czer, L.S., Marban, L., Mendizabal, A., Johnston, P.V., Russell, S.D., Schuleri, K.H., Lardo, A.C., Gerstenblith, G., and Marban, E. Intracoronary cardiosphere-derived cells for heart regeneration after myocardial infarction (CADUCEUS): a prospective, randomised phase 1 trial. Lancet 379, 895, 2012.
148. Kaushal, S., and Wehman, B. Stem cells on a new stage: treatment of hypoplastic left heart syndrome. J Thorac Cardiovasc Surg 150, 1209, 2015.

149. Tarui, S., Ishigami, S., Ousaka, D., Kasahara, S., Ohtsuki, S., Sano, S., and Oh, H. Transcoronary infusion of cardiac progenitor cells in hypoplastic left heart syndrome: threeyear follow-up of the Transcoronary Infusion of Cardiac Progenitor Cells in Patients With Single-Ventricle Physiology (TICAP) trial. J Thorac Cardiovasc Surg 150, 1198, 2015.

150. Ishigami, S., Ohtsuki, S., Tarui, S., Ousaka, D., Eitoku, T., Kondo, M., Okuyama, M., Kobayashi, J., Baba, K., Arai, S., Kawabata, T., Yoshizumi, K., Tateishi, A., Kuroko, Y., Iwasaki, T., Sato, S., Kasahara, S., Sano, S., and Oh, H. Intracoronary autologous cardiac progenitor cell transfer in patients with hypoplastic left heart syndrome: the TICAP prospective phase 1 controlled trial. Circ Res 116, 653, 2015.

151. Tarui, S., Sano, S., and Oh, H. Stem cell therapies in patients with single ventricle physiology. Methodist Debakey Cardiovasc J 10, 77, 2014.

152. Bergmane, I., Lacis, A., Lubaua, I., Jakobsons, E., and Erglis, A. Follow-up of the patients after stem cell transplantation for pediatric dilated cardiomyopathy. Pediatr Transplant 17, 266, 2013.

153. Rupp, S., Bauer, J., Tonn, T., Schachinger, V., Dimmeler, S., Zeiher, A.M., and Schranz, D. Intracoronary administration of autologous bone marrow-derived progenitor cells in a critically ill two-yr-old child with dilated cardiomyopathy. Pediatr Transplant 13, 620, 2009.

154. Rupp, S., Zeiher, A.M., Dimmeler, S., Tonn, T., Bauer, J., Jux, C., Akintuerk, H., and Schranz, D. A regenerative strategy for heart failure in hypoplastic left heart syndrome: intracoronary administration of autologous bone marrow-derived progenitor cells. $\underline{J}$ Heart Lung Transplant 29, 574, 2010.

155. Burkhart, H.M., Qureshi, M.Y., Peral, S.C., O’Leary, P.W., Olson, T.M., Cetta, F., Nelson, T.J., and Wanek Program Clinical Pipeline, G. Regenerative therapy for hypoplastic left heart syndrome: first report of intraoperative intramyocardial injection of autologous umbilical-cord blood-derived cells. J Thorac Cardiovasc Surg 149, e35, 2015.

Address correspondence to: Ming-Sing Si, MD

Department of Cardiac Surgery University of Michigan C.S. Mott Children's Hospital 1540 E. Hospital Drive, SPC 4204

Floor 11, Room 735

Ann Arbor, MI 48109-4204

E-mail: mingsing@umich.edu

Received: April 7, 2016

Accepted: May 26, 2016

Online Publication Date: June 29, 2016 
This article has been cited by:

1. Hyokyoung Kwon, Minjeong Kim, Yunmi Seo, Yae Seul Moon, Hwa Jeong Lee, Kyuri Lee, Hyukjin Lee. 2018. Emergence of synthetic mRNA: In vitro synthesis of mRNA and its applications in regenerative medicine. Biomaterials 156, 172-193. [Crossref] 